\title{
STRATEGI PENANGGULANGAN KEBAKARAN PADA LAHAN GAMBUT DENGAN MENGGUNAKAN PENDEKATAN EKO-TEKNOLOGI PADA MASYARAKAT PETANI DI DESA RIMBO PANJANG KECAMATAN TAMBANG KABUPATEN KAMPAR PROVINSI RIAU
}

\author{
Saktioto $^{1, *}$, Defrianto $^{1}, \operatorname{Riad~Syech}^{1}$, Syahril $^{2}$, Joko Risanto $^{3}$ \\ 1, Jurusan Fisika, FMIPA, \\ 2, Jurusan Pendidikan Fisika, FKIP \\ 3, Jurusan Komputer, FMIPA \\ Universitas Riau Kampus Bina Widya Pekanbaru \\ Jl. Prof. Muchtar Luthfi Pekanbaru, 28293 \\ *E-mail korespondensi: saktioto@yahoo.com
}

\begin{abstract}
People who care about the environment always reject the use of peat land for large-scale plantation areas, because this can cause an increase in carbon gas and can even cause damage to peat land in Rimbo Panjang Village, Tambang District, Kampar Regency. that there was an event of a land fire which almost hit the residential area in Rimbo Panjang village, Kec. Kampar District Mine on February 24, 2015. That there are complaints from the community in Rimbo Panjang village, Kec. Kampar Regency Mine about environmental conditions or smog. The implementation of Eco-Technology can protect the environment of peatlands to maintain sustainability and avoid fire from peatlands and regulate groundwater management on peatlands.
\end{abstract}

Keywords: Eco-technology, fire, peatland.

\begin{abstract}
ABSTRAK
Masyarakat yang peduli lingkungan selalu menolak pemanfaatan lahan gambut untuk areal perkubunan berskala besar, karena hal ini dapat menyebabkan meningkatnya gas karbon bahkan dapat menyebabkan kerusakan lahan gambut di Desa Rimbo Panjang Kecamatan Tambang Kabupaten Kampar. bahwa ada peristiwa kebakaran lahan yang hampir mengenai pemukiman penduduk di desa Rimbo Panjang Kec. Tambang Kabupaten Kampar pada 24 Februari 2015. Bahwa adanya keluhan masyarakat di desa Rimbo Panjang Kec. Tambang Kabupaten Kampar tentang kondisi lingkungan atau kabut asap. Penerapan Eko-Teknologi bisa menjaga lingkungan lahan gambut agar tetap terjaga kelestariannya dan menghindari kebakaran lahan gambut serta mengatutr tata air tanah di lahan gambut.
\end{abstract}

Kata kunci : Eko-teknologi, kebakaran, lahan gambut.

\section{PENDAHULUAN}

Desa Rimbo Panjang sebagai salah satu desa di Kecamatan Tambang Kabupaten Kampar secara geografis memiliki kondisi dataran rendah dan didominasi dengan areal gambut. Areal gambut yang kering akan mudah terbuka terbakar, dan jika terjadi kebakaran di lahan gambut maka sangat sulit padamnya. Gambar 1 adalah peristiwa kebakaran lahan di desa Rimbo Panjang yang terjadi pada 24 Februari 2015.
Berdasarkan analisis situasi di atas, maka perlu dilakukan penyuluhan pengelolaan lahan gambut untuk pencegahan kebakaran di lahan gambut. Penyuluhan ini akan menciptakan lingkungan yang berkualitas sehingga dapat meningkatkan pemahaman masyarakat tentang antisipasi pencegahan kebakaran lahan.

Identifikasi yang ada di desa Rimbo Panjang Kecamatan Tambang Kabupaten Kampar bahwa ada peristiwa kebakaran lahan yang hampir mengenai pemukiman penduduk di desa Rimbo Panjang Kec. Tambang Kabupaten Kampar pada 24 Februari 2015. 
Bahwa adanya keluhan masyarakat di desa Rimbo Panjang Kec. Tambang Kabupaten Kampar tentang kondisi lingkungan atau kabut asap [1].

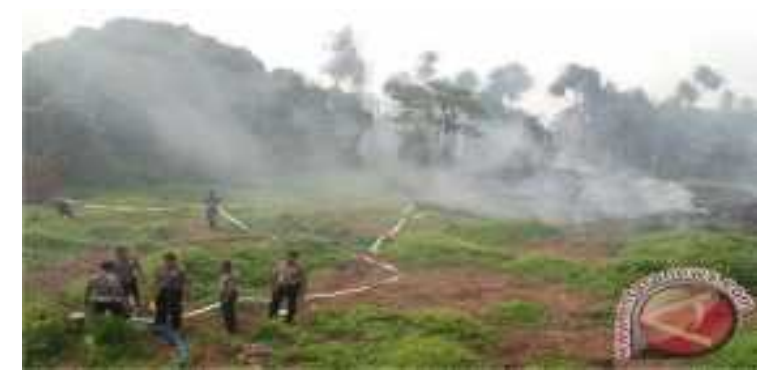

Gambar 1. Kebakaran lahan di desa Rimbo Panjang Tahun 2015 (www.antaranews.com).

Berdasarkan analisis di atas, maka Saktioto dkk merencanakan akan melakukan kegiatan di desa Rimbo Panjang Kecamatan Tambang Kampar Kabupaten Kampar, hal ini didukung oleh pengalaman Tim yang telah banyak melakukan kegiatan pengabdian yang dapat mendukung suksesnya kegiatan ini.

Berdasarkan identifikasi diatas maka permasalahan yang ada di desa Rimbo Panjang Kecamatan Tambang Kabupaten Kampar , yaitu:

a. Adanya peristiwa kebakaran lahan yang hampir mengenai pemukiman penduduk di desa Rimbo Panjang Kec. Tambang Kabupaten Kampar pada 24 Februari 2015.

b. Adanya keluhan masyarakat di desa Rimbo Panjang Kec. Tambang Kabupaten Kampar tentang kondisi lingkungan atau kabut asap.

c. Masyarakat petani belum mengenal EkoTeknologi untuk penanggulangan kebakaran hutan.

Porositas tanah gambut adalah factor yang berhubungan dengan kemampuan air untuk menyimpan air, sehingga akan menjaga kelembaban tanah gambut. Kelembaban tanah gambut ini harus terus dipertahankan agar tidak terjadi kebakaran pada lahan gambut. Nilai porositas tanah gambut dapat ditulis:

Porositas adalah perbandingan antaravolume ruang pori terhadap volume total tanah. Porositas ini dinyatakan dalam persen
(\%).Porositas ditentukan secara langsung dengan uji laboratorium.Dimana nilai porositas dapat diketahui dengan nilai bobot isi dan berat jenis partikel (BJP). Sehingga porositas dapat dihitung dengan rumus (Sundema, 2010).

$$
\text { Porositas }(\%)=(1-\text { Bobot Isi /BJP }) \times 100 \%
$$

\section{METODOLOGI PENELITIAN}

Metode yang dilakukandalam penyuluhan ini adalah metode ceramah dan praktek yaitu dengan mendesain sistem teknologi ekohidro yang dilakukan di desa Rimbo panjang Kecamatan Tambang Kabupaten Kampar, khususnya yang berkaitan dengan permasalahan untuk meningkatkan kualitas lingkungan hidup dalam hal penanggulangan kebakaran lahan gambut di desa Rimbo Panjang Kecamatan Tambang Kabupaten Kampar. Penyuluhan diarahkan melalui sosialisasi teknologi ekohidro, penggunaan Eko-Teknologi untuk pengelolaaan lingkungan dengan demikian kebakaran lahan gambut dapat dicegah [2].

Langkah -langkah kegiatan pengabdian ini adalah sebagai berikut:

Langkah 1: Peserta pelatihan diberikan materi mengenai arti pentingnya Eko Teknologi.

Langkah 2: Peserta diberikan kesempatan untuk menanyakan materi yang belum jelas.

Langkah 3: Peserta berlatih untuk memahami Eko Teknologi

Langkah 4: Peserta pelatihan melakukan analisis untuk diberikan masukan dan perbaikan Eko Teknologi.

\section{HASIL DAN ANALISA}

Pelaksanaan pengabdian ini di bagi atas dua tahapan yaitu:

\section{Tahapan di Kelas}


Tahapan ini terdiri dari penyampaian materi di ruangan/aula Desa Rimbo Panjang Kecamatan Tambang Kabupaten Kampar Provinsi Riau.

\section{Tahapan di Lapangan}

Tahapan ini untuk praktek langsung penanggulangan kebakaran di lahan Gambut yang ada di Desa Rimbo Panjang Kecamatan Tambang Kabupaten Kampar Provinsi Riau.

Tahapan di ruang kelas/aula Desa Rimbo panjang ini diawali dengan memberikan materi penyuluhan tentang strategi penanggulangan kebakaran hutan dan lahan gambut.Masyarakat dengan antusias memperhatikan materi penyuluhan yang disampaikan oleh Prof.Dr. Saktioto,M.Phil, seperti ditunjukkan pada Gambar 2.

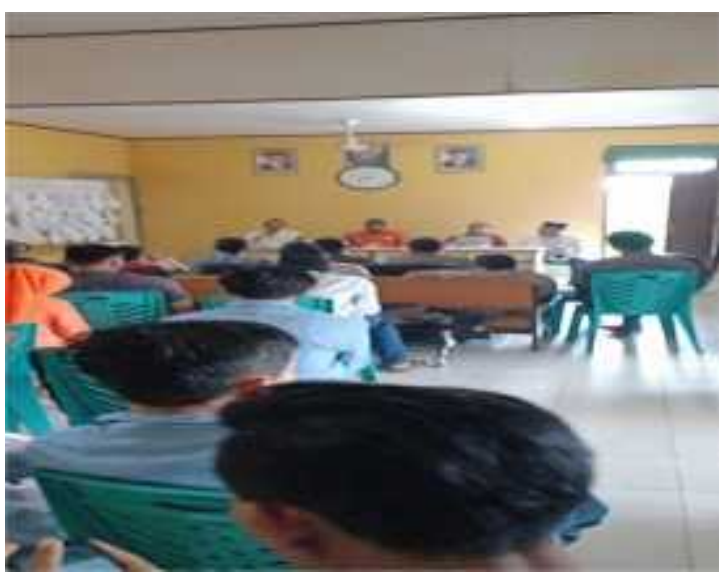

Gambar 2. Pemaparan Materi Penyuluhan oleh Tim Pengabdian

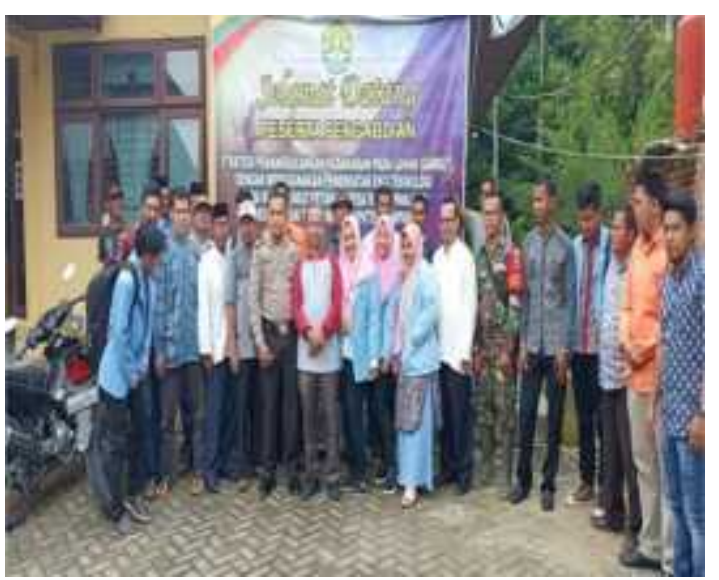

Gambar 3. Antusias peserta pengabdian dari unsur kepolisian, Babinsa dan tokoh masyarakat.
Penyuluhan ini juga dihadiri oleh aparat kepolisian dan Babinsa, serta tokoh masayarakat, hal ini menunjukkan komitmen pemerintah dan masyarakat Desa Rimbo Panjang dalam mengatasi masalah kebakaran lahan gambut (Gambar 3). Kegiatan penyuluhan ini juga dihadiri oleh unsur kemahasiswaan untuk maksud transfer ilmu agar mahasiswa dapat menerapkannya di lapangan.

Untuk memudahkan masyarakat memahami teknologi Eko Hidro untuk penanggulangan kebakaran lahan Gambut, maka timlangsung memperagakan bagaimana teknik Eko Hidro dipraktekkan di lahan gambut, seperti ditunjukkan pada Gambar 4 dan Gambar 5.

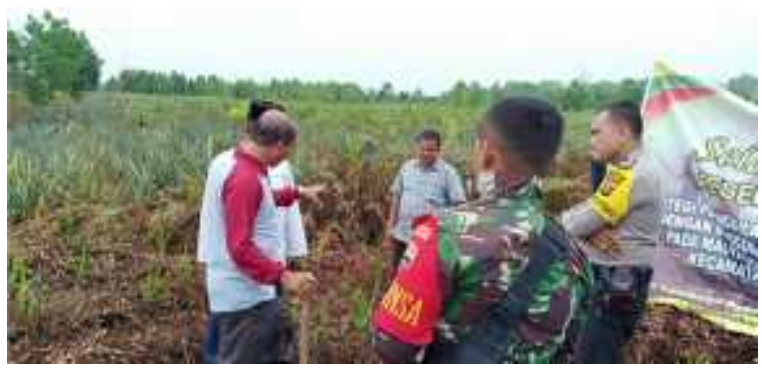

Gambar 4. Tim sedang memberikan contoh pelaksanaan Eko Hidro di lahan gambut.

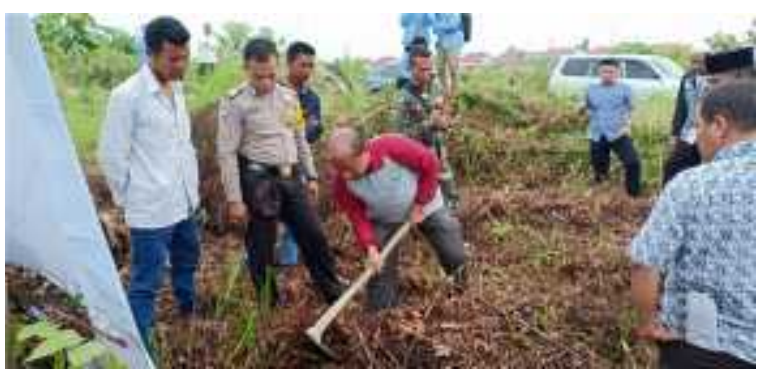

Gambar 5. Tim menunjukkan praktek Eko Teknologi Di lapangan lahan gambut.

Pengelolaan Eko-Teknologi untuk pengelolaan muka air tanah pada kawasan gambut adalah bermanfaat untuk [3]:

1. Penghijauan areal kawasan gambut.

2. Menghindari kebakaran lahan Gambut

3. Mengatasi kelembabman arela gambut

4. Mengurangi emisi karbon

5. Mempertahankan tinggi muka air tanah 
6. Menggunakan system parit sisir menjaga aliran air.

Kepentingan Eko-Teknologi untuk kawasan di lahan gambut bertujuan:

1. Lokasi lahan gambut terhindar dari kerusakan.

2. Memajukan ekonomi penduduk disekitar kawasan gambut.

Eko-Teknologi untuktata kelola muka air di areal gambut bermanfaat agar [4]:

1. membuka jalur daerah yang tertutup.

2. mempercepat lalu lintas jalan.

3. mencegah kerusakan lahan gambut.

4. mempertahankan keberagaman tumbuhan,

5. menambah keanekaragaman tanaman.

6. meminimalkan gas karbon.

Pengelolaan air di lahan gambut berguna untuk [5]:

1. menganalisa laju perubahan tanaman di lahan gambut.

2. menganalisa kelembabanlahan gambut.

3. memberi solusi terhadap bahaya kekurangan air di lahan gambut serta dampak dari kelebihan air.

5. memberikan solusi terhadap pengelolaan air di lahan gambut.

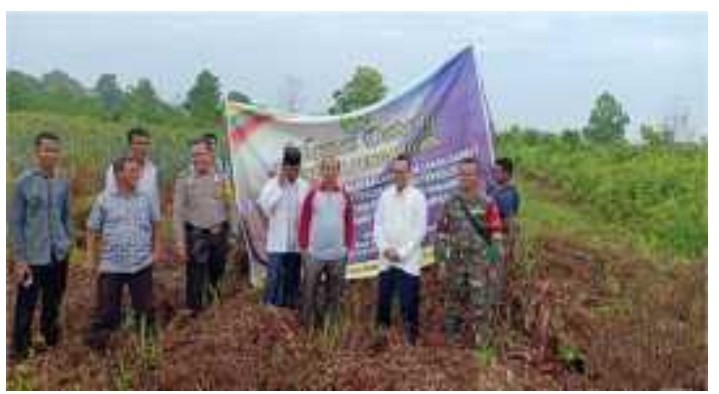

Gambar 6. Foto Bersama di lapangan lahan gambut desa Rimbo panjang.
Setelah tim memberikan contoh pelaksanaan Eko Teknologi dilapangan lahan gambut, maka masyarakat dapat memahami cara kerja Eko- teknologi, masyarakat sangat puas dengan hasil uji langsung di lahan gambut ini. Rasa kepuasan masyarakat ini ditunjukkan dengan banyaknya pertanyaan.Tahapan ini diakhiri dengan foto bersama di lapangan lahan gambut.

\section{KESIMPULAN}

Eko-Teknologi yang diterapkan dilahan gambut telah dapat menjadikan kawasan lahan gambut di Desa Rimbo Panjang Kabupaten Kampar Provinsi Riau terbebas dari bahaya kebakaran hutan dan terhindar dari efek kemarau. Masyarakat petani di desa Rimbo Panjang telah diberikan penyuluhan tentang aplikasi Eko-Teknologi.

\section{DAFTAR PUSTAKA}

1. Larin, D. (2006). Kebakaran Hutan dan Lahan./http:/www.google.com.Di Akses pada Tanggal 20 November 2018.

2. Jahrin, S. T. (2007). Kebakaran Hutan dan Lahan Cenderung Masih Akan Terjadi.

3. Budi I. S. (2012). Training On: Water Management For Forest Plantation In Tropical Peatlands. Halaman 5.

4. Nicolas, Marc. V. J., \& Roderick, M. B. (1999). Pendekatan Kebakaran Gambut dan Batubara di Propinsi Sumatera Selatan, Indonesia. Proyek Pencegahan.

5. Notohadinegoro, T. (1996). Perspektif Pengembangan Lahan Basah. Fakultas 